\title{
Genetic diversity and population structure of Vernonia [Vernonia galamensis (Cass.) Less] populations from Ethiopia revealed by SSR markers
}

Alemneh Mideksa Egu ( $\square$ alemnehmideksa@gmail.com )

Addis Ababa University https://orcid.org/0000-0002-0755-6525

Kifle Dagne

Addis Ababa University College of Natural Sciences

Kassahun Tesfaye

Addis Ababa University College of Natural Sciences

Xuebo Hu

Hauzohang Agricultural University

Research article

Keywords: Allelic pattern, dendrogram, genetic diversity, polymorphism, simple sequence repeat, vernonia

Posted Date: December 16th, 2019

DOI: https://doi.org/10.21203/rs.2.18928/v1

License: (c) (i) This work is licensed under a Creative Commons Attribution 4.0 International License. Read Full License 


\section{Abstract}

\section{Background}

Vernonia (Vernonia galamensis) is a potential novel industrial crop due to high demand for its natural epoxidised oil, which can be used for the manufacturing of oleochemicals such as paints, plastic formulations (polyvinyl chloride), and pharmaceutical products. This study is initiated for the systematic and intensive genetic diversity assessment of $V$. galamensis accessions by SSR molecular markers to minimize the existing research gaps, provide a clue for germplasm conservation and further research.

\section{Results}

Twenty SSR markers were used for genetic diversity analyses of 150 individual V. galamensis accessions representing 10 populations, from which a total of 79 bands were identified across the entire loci. All the loci used showed high polymorphism that ranged from 0.50 to 0.96 , while the mean observed heterozygosity $(\mathrm{Ho})$ was 0.15 across all the 20 markers evaluated. The molecular variance analysis (AMOVA) showed significant variations despite low differentiation among populations which accounted for only $11 \%$ of the total variations. Populations clustering showed that the dendrogram and principal coordinate's analysis roughly classified the 150 accessions into four groups. However, the Bayesian model-based clustering (STRUCTURE) grouped into $6(K=6)$ major gene pools. These analyses showed accessions collected from the same region of origin did not often grouped entirely together within a given major groups.

\section{Conclusions}

The result suggested that the markers applied to ten populations, in which East Showa and East Harerghe revealed higher genetic diversity, signaled that these areas are the hotspots for in-situ conservation of $V$. galamensis. In addition, the values of SSR markers such as heterozygosity, Shannon's index, polymorphic information content, and population clusters are important baseline information for future $V$. galamensis cultivation, breeding and genetic resource conservation endeavors in Ethiopia.

\section{Background}

Vernonia (Vernonia galamensis (Cass.) Less.; $2 \mathrm{n}=18$ ) belongs to the family Asteraceae (Compositeae), a potential novel industrial crop due to the high demand for its natural epoxidised oil [1-5]. Vernonia galamensis subsp. galamensis variety ethiopica M. Gilbert was first identified by Perdue in 1964 in Eastern Ethiopia [6, 7]. Seeds of Vernonia species are the major sources of naturally occurring epoxidised fatty acids and other essential fatty acids such as linoleic acid, oleic acid, palmitic acid, stearic acid and trace amounts of arachidic acid $[9,10,11-14]$.

Studying genetic diversity of crop plants including V. galamensis is a valuable tool for effective utilization, conservation, management, and improvement during breeding and selection $[15,16]$. Molecular markers are valuable tools for discrimination between accessions, easy and cost-effective to measure and not influenced by environmental factors. Microsatellites (SSR) markers have efficient advantages over other DNA markers that they are highly polymorphic, co-dominant inheritance with high mutation rates, relatively abundant and good genome coverage, which used to investigate taxonomical, genetic diversity and evolutionary relationship $[17,18]$. However, SSR markers have limitations such as genomic sequencing is needed to design specific primers; it is also not very cost-effective and requires much discovery and optimization for each species before use [19]. To date, this study was the first report that used SSR markers to study the genetic diversity of $V$. galamensis.

In Ethiopia, geo-ecological conditions are favorable for the cultivation of $V$. galamensis for the use as a source of raw material for agro-processing industries. However, the plant is neglected and considered only as a wild weed colonizing disturbed and bare agricultural lands [3]. As a result, the crop is not cultivated in any of the collection sites and/or elsewhere in the country. Moreover, lack of attention, negligence in research and conservation, priority has been given to other major crop plants while the potential industrial values of $V$. galamensis is underestimated and underexploited. The plant is also under threat of continued genetic erosion. This study is, therefore, initiated for the systematic and intensive genetic diversity evaluation and characterization of $V$. galamensis accessions by molecular analysis using SSR markers to minimize the existing research gaps and provide a clue for germplasm conservation and further research. 


\section{Methods}

\section{Plant material}

A total of $150 \mathrm{~V}$. galamensis accessions, representing 10 populations, were randomly collected from their diverse agro-ecologies of the three-potential growing regional states of Ethiopia (Figure 1; Table 1). The samples identified were confirmed with the descriptions available in the Flora of Ethiopia and Eritrea. Most of the study materials were collected from the field and, others were assembled from the Ethiopian Biodiversity Institute and Wondo Genet Agricultural Research Center

At each collection area, seed samples were collected from plants and kept in separate bags to ensure that the distance between any two collection sites was about $5-10 \mathrm{Km}$. From collection areas observations, $V$. galamensis naturally grows in hilly/depression, along the roadside, in the valley, in farmlands, in the forest, in the compounds of mosques and churches. The collections were done by taking either seed samples of the individual flower heads or seeds from plants with all matured flowers, and then accessions were threshed, cleaned and documented. $V$. galamensis was not cultivated in any of the collection sites.

\section{Plant material collection and DNA extraction}

Fresh young leaves of $150 \mathrm{~V}$. galamensis accessions were collected from individual plants that were grown at experimental sites, representing 10 populations. Collected leaf samples were put in a sealed bag envelope and dried with silica gel (with 1:10 ratio of leaf samples to silica gel), then kept under room temperature until used for later DNA extraction according to Gilbert et al. [20]. The dried leaf samples were transported to Huazhong Agricultural University, China for genetic analysis. The total genomic DNA extraction was made according to the modified CTAB protocol of Doye and Doye [21]. Extracted DNA was visualized on a 1\% (w/v) agarose gel and quantified spectrophotometrically using a Nanodrop ${ }^{\circledR} 2000$ (Thermo Scientific, USA). Finally, it was stored at $-20^{\circ} \mathrm{C}$ for further use.

\section{Polymerase Chain Reaction (PCR) Amplification}

The twenty SSR markers used for this study were selected based on their high polymorphism from the work of Narina et al. [22] (Table 2). The amplification reaction was performed with a thermal cycler using 96-well plates ( $\mathrm{T} 100^{\mathrm{TM}}$ Thermal Cycler) in a total volume of $10 \mu \mathrm{l}$ reaction mixture, containing $100 \mathrm{ng} / \mathrm{ml}$ of template DNA, $5 \mu \mathrm{l} 2$ x Taq PCR master mix (Vazyme P213-01, China), $1 \mu \mathrm{l}$ of forward and reverse primers and $3.0 \mathrm{ml}$ of double-distilled water. The PCR amplification was programmed at an initial denaturation step of 5 minutes at $94^{\circ} \mathrm{C}$ followed by 35 cycles of $30 \mathrm{~s}$ denaturation at $94^{\circ} \mathrm{C}$, annealing at $56 / 58^{\circ} \mathrm{C}$ (depending on primers) for $30 \mathrm{~s}$, initial extension at $72{ }^{\circ} \mathrm{C}$ for 1 minute and final extension at $72{ }^{\circ} \mathrm{C}$ for 5 minutes. The amplified DNA samples were stored at $4{ }^{\circ} \mathrm{C}$ until it was loaded on $3 \%$ agarose gel electrophoresis for visualization.

\section{Band Scoring and Analysis}

The amplified products were visually scored based on their migration in comparison with the standard size DNA (100 bp DNA ladder) photographed under UV gel illumination (Gel Doc ${ }^{T M}$ with Image Lab ${ }^{T M}$ software, BIO-RAD). The genetic diversity for each allele such as the number of different alleles $(\mathrm{Na})$, the effective number of alleles $(\mathrm{Ne})$, Shannon's diversity index (I), observed heterozygosity $(\mathrm{Ho})$, expected heterozygosity $(\mathrm{He}), \mathrm{F}$-statistics values $\left(\mathrm{F}_{\mathrm{is}}, \mathrm{F}_{\mathrm{it}}\right.$ and $\left.\mathrm{F}_{\mathrm{st}}\right)$, polymorphic information content (PIC), random segregation and distribution (Hardy-Weinberg equilibrium) of each genotype within the populations for each locus, Nei's genetic identities (Ji), genetic distances (Ds) and gene flow (Nm) in V. galamensis populations were performed using GeneAlex version 6.503 software [23].

Simple matching dissimilarity coefficient-based Unweighted Pair Group Method with Arithmetic Mean (UPGMA) and NeighborJoining (NJ) tree were computed using DARwin version 6.0.19 software [24], and the significant was tested based on 1000 bootstraps. The resulting trees were displayed using Fig Tree version. 1.4.4 [25]. Each of the four clusters comprised collections of geographic regions of origin. A Bayesian model-based cluster analysis was performed using STRUCTURE version 2.3.4 software [26]. Each of the groups of populations composed of individual plants from different collection zones/geographic regions of origin. To determine the most likely number of populations (K), a burn-in period of 50,000 was used in each run, and data were collected over 500,000 Markov Chain Monte Carlo (MCMC) replications for $\mathrm{K}=1$ to $\mathrm{K}=10$ using 20 iterations for each $\mathrm{K}$. The optimum $\mathrm{K}$ value was determined according to Evanno et al. [27] using the web-based (http://tyloro.biology.ucla.edu\structure Harvester\) STRUCTURE HARVESTER ver. 0.6.92 [28]. The results generated by this software were visualized in a graphical bar plot using Clumpak beta version (http://www.clumpak.tau.ac.il/) [29]. 


\section{Results}

\section{SSR Polymorphism}

Twenty SSR markers were used for the characterization and genetic diversity analysis of the $150 \mathrm{~V}$. galamensis accessions, all of which were polymorphic (Table 3). The results of diversity parameters showed a high level of polymorphism among the 20 SSR markers. Polymorphic information content (PIC) values ranged between 0.50 and 0.96 with an average of 0.76 . Microsatellite markers such as $\mathrm{Vg}-002$ and $\mathrm{Vg}-011$ showed the highest polymorphism with 0.96 and 0.93 , respectively (Table 3 ). A total of 79 alleles were identified, varied from 2 to 6 with an average of 3.9 alleles per locus. The maximum number of effective alleles ( $\mathrm{Ne})$ was $4.79(\mathrm{Vg}-003)$ and the least number of effective alleles was 1.99 ( $\mathrm{Vg}-016)$. The highest major allele frequency (MAF) (0.85) was recorded by locus $\mathrm{Vg}-001$ and the least MAF was $(0.45)$ recorded by locus $\mathrm{Vg}-003$. The observed heterozygosity (Ho) values were quite low ranging between $0.05(\mathrm{Vg}-021)$ and $0.36(\mathrm{Vg}-003)$ with an average of 0.16 across all the 20 markers evaluated. The expected heterozygosity $(\mathrm{He})$ mean was 0.50 (Table 3). Fixation index $(\mathrm{F})$ ranged from $0.25(\mathrm{Vg}-001)$ to $0.89(\mathrm{Vg}-021)$ with an average of 0.68. Finally, Shannon-Weaver's information indices (I) ranged from 0.86 to 1.67 (Table 3). On the other hand, East Showa and East Harerghe had the highest in effective alleles, heterozygosity, genetic diversity (Shannon diversity index) and fixation index (Table 4).

\section{Analysis of molecular variance (AMOVA)}

The analysis of molecular variance (AMOVA) indicated that the genetic variation within populations contributed more to genetic diversity than that among populations (Table 5). The AMOVA showed $67 \%$ of the total variation was attributed to genetic variability among individuals from different populations, whereas $22 \%$ was due to variation among individuals within the same population. In contrast, a smaller portion (11\%) was among the populations variations.

\section{Genetic distance between populations}

The Nei's [30] standard genetic distance (GD) between populations ranged from 0.24 to 0.57 . The highest pairwise genetic distance was observed between populations of Borena and East Harerghe (0.57), followed by between populations of Sidama and West Harerghe (0.54). The minimum pairwise genetic distance was observed between populations of Borena and Konso (0.24) (Table 6).

\section{Cluster, principal co-ordinate analysis (PCOA) and population structure}

Clustering analysis, which was performed based on the allelic frequency, grouped the 150 accessions into four (4) major clusters from the main node using neighbor-joining, with the DARwin 6.0.19 software programs. Each of the four clusters comprises individual plants from different zones (geographic regions). The first and the third cluster further divided into sub-clusters according to their geographic origin (Figure 2).

The first cluster constituted 39 accessions, the second cluster contained 42 accessions, while cluster three was characterized as the smallest group in clustering comprising of 15 accessions and the fourth cluster was the major group of clustering and comprised of 54 accessions (Figure 2). The cluster analysis revealed that accessions from different populations (collection sites) clustered together with no clear pattern of geographic origins. The principal coordinate analysis (PcoA) showed that the majority of samples were placed at the center of a two-dimensional coordinate plane and roughly forms four groups (Figure 3 ). The first three axes of the PCoA together accounted for $33.02 \%$ of the total variation.

\section{Population structure analysis}

Analysis of population structure distinguished the $150 \mathrm{~V}$. galamensis accessions using a model-based Bayesian approach with the highest $\Delta K$ Value that ranged from $\mathrm{K}=1$ to $\mathrm{K}=10$ and 20 iterations for each $\mathrm{K}$. According to Evanno et al. [27] and Gilbert et al. [31], STRUCTURE outputs were predicted $\mathrm{K}=6$, most likely selected to describe the genetic structure of the $150 \mathrm{~V}$. galamensis accessions (Figure 4). Based on this value, population structure (Clumpak result) revealed that accessions collected from the same region of origin did not often grouped entirely together within a given major group. There was a wide admixture in structuring of $\mathrm{V}$. galamensis populations.

\section{Discussions}


Vernonia galamensis is a potential novel industrial crop containing naturally occurring epoxidized oil. However, its potential values are neglected, underestimated and underexploited. In addition, it is also exposed to genetic erosion. Therefore, assessment of genetic diversity with SSR markers generally in plants and particularly in $\mathrm{V}$. galamensis is important for in-situ and ex-situ conservation and for efficient management of genetic diversity, for selection and improvement of the available genetic resource. The SSR marker-based study showed considerable genetic diversity. A total of 79 alleles with an average of 3.9 alleles were detected in this study, which was higher than the one reported by Ramalema et al. [13] in $V$. galamensis. The author also stated that less genetic diversity was observed among different Vernonia lines. According to Aikpokpodion et al. [32], a total of 29 bands were detected using five RAPD primers in genus Vernonia. Hence, the large number of alleles detected in the present study indicated the suitability of microsatellites for genetic linkage and QTL mapping of desirable traits applied to marker-assisted selection (MAS) in breeding programmes.

Polymorphic information content (PIC) is generally used for the characterization of marker polymorphism. In this study, the PIC values ranged between $0.50(\mathrm{Vg}-005)$ and $0.96(\mathrm{Vg}-002)$ with an average of 0.76 , which was higher than that reported by Ramalema et al. [13] using RAPD markers in V.galamensis. Microsatellite markers such as Vg-002 and Vg-011 showed the highest polymorphism with 0.96 and 0.93 , respectively. Aikpokpodion et al. [32] also indicated that PIC was ranged from 0.27 to 0.78 in $\mathrm{V}$. galamensis accessions. This indicates that the majority of markers were able to distinguish differences among the studied $\mathrm{V}$. galamensis accessions. For most of the loci, expected heterozygosity $\left(H_{e}\right)$ values were higher than that of observed heterozygosity $\left(H_{o}\right)$, revealing a high homozygosity at the given loci among the accessions. The diversity parameters showed high level of polymorphism among the 20 SSR markers, favoring the genetic variation within V. galamensis collection. In addition, East Showa and East Harerghe had the highest in effective alleles, heterozygosity, genetic diversity (Shannon diversity index) and fixation index. Hence, the two sites are the hotspot for in-situ and ex-situ conservation of V.galamensis.

\section{Genetic Differentiation and Gene Flow}

AMOVA demonstrated that $V$. galamensis had low variation among the population (11\%). On the other hand, $67 \%$ of the total variation was attributed to genetic variability among individuals from different populations and $22 \%$ was due to variation among individuals within the same population. The result is similar to the previously reported in Vernonia species [33]. According to IPGRI and Cornell University [34], Fst value ranging from 0 to 0.05 is small in genetic differentiation, from 0.05 to 0.15 is moderate, and from 0.15 to 0.25 is large, and greater than 0.25 is very large genetic differentiation among populations in terms of allele frequencies. In line with this, the extent of genetic differentiation among the ten populations in terms of allele frequencies measured was moderate $\left(F_{s t}=0.101\right)$, which implies the presence of moderate gene flow among populations in different regions.

Genetic distance is the measure of the allelic substitutions per locus that have occurred during the separate evolution of two populations. In this study, the largest genetic distance was observed between Borena and East Harerghe (0.57) populations, while the minimum genetic distance was observed between Borena and Konso (0.24). The overall magnitude of the pairwise population matrix of Nei genetic distance was relatively low [30].

\section{Clustering and principal co-ordinates analysis among Vernonia galamensis accessions}

In the present study, a dendrogram tree was constructed based on the 150 accessions of $V$. galamensis collected from different geographic and agro-ecological regions. V.galamensis accessions were clustered into four (4) major clusters based on the allelic frequency. Cluster 1 was comprised of 39 accessions, the second cluster characterized as the second major clustering, contained 42 accessions, the third cluster composed of 15 accessions, and the fourth groups consisted of the major clustering which comprised 54 accessions that were collected from different regions of origin. The cluster analysis revealed a poor clustering pattern was observed. Hence, accessions collected from different geographic regions/zones of origins were clustered together, since clusters did not follow a clear pattern of geographic origins, which may imply the presence of gene flow between and within populations/regions/collection sites. Similarly, Nwakanma et al. [33] reported that 49 Vernonia lines fingerprinted using RAPD markers were grouped into four major clusters with no clear-cut separation among accessions related to their origin. Aikpokpodion et al. [32] also reported that genus Vernonia grouped into four major clusters and showed the existence pattern of relationships between geographical origins and genetic diversity. 
Principal components (PC) analysis explores complex data sets and transforms a number of associated variables into a smaller number of PCs. In the present investigation, the principal component analysis revealed that the majority of samples were placed at the center of a two-dimensional coordinate plane and roughly forms four groups with a total variation of $30.04 \%$. This, in turn, agrees with the results of the $\mathrm{NJ}$ dendrogram in which there was no unique clustering among accessions from the same population/collection areas. The presence of gene flow between and within populations/collection areas, accompanied by the prevalence of inter-gene pool introgressions/hybrids between the gene pools of origin may be the most probable explanation behind the mixed clustering of accessions from different populations/collection areas together. Although UPGMA and PCoA analyses also showed a certain level of population clustering according to their geographical regions, the clustering pattern is weak, not clustered by their regions of origin.

\section{Populations genetic structure in Vernonia galamensis}

The structure analyses of $150 \mathrm{~V}$. galamensis accessions using a Bayesian-model based approach with the highest $\Delta K$ Value, according to Gilbert et al. [31] and Evanno et al. [27] method. The samples from 10 collection zones were inferred into six $(K=6)$ structure outputs. The structure analysis revealed a close relationship (weak sub-division) of the population from 10 collection zones, and in general, six inferred groups $(K=6)$ with potential admixtures have been observed. It is interesting to indicate that all individual plants analyzed have alleles originated from the six clusters, which supports the presence of a strong gene flow that led to poor population differentiation. Hence, accessions collected from the same region of origin did not often group entirely together within a given major groups. There was a wide admixture in the structuring of $V$. galamensis populations, and population genetic structure study using SSR markers, which is the first report in V.galamensis. Most of the magnitudes identified for the SSR markers were important information for $V$. galamensis cultivation, breeding and genetic resource conservation.

\section{Conclusions}

The present molecular genetic diversity analysis by using SSR markers was the first report in $\mathrm{V}$. galamensis. All the twenty markers used were polymorphic in the population studied. The markers detected a large number of alleles and higher expected heterozygosity than observed heterozygosity. Generally, the results of the present study showed that there was ample allelic diversity among the $V$. galamensis accessions studied. The UPGMA and PCoA showed a certain level of populations clustered according to their geographical regions, but the pattern of clustering was weak as it did not show clustering by their regions of origin. Most of the values identified for the SSR markers were important baseline information for future $\mathrm{V}$. galamensis cultivation and breeding/genetic resource conservation endeavors in Ethiopia. As the present study used only 20 SSR markers, it was not enough to cover all the actual genetic diversity in $\mathrm{V}$. galamensis. Hence, more such markers, as well as other appropriate and up-to-date molecular marker systems are important to generate reliable and exploitable data in this regard for the use in breeding and conservation programs.

\section{Abbreviations}

AMOVA: Analysis of molecular variance; CTAB: Cetyltriethyl ammonium bromide; He: Expected heterozygosity; Ho: observed heterozygosity; NJ: Neighbor joining; PCoA: Principal coordinate analysis; PIC: Polymorphic information content; SSR: simple sequence repeat; UPGMA: Unweighted pair group with arithmetic mean

\section{Declarations}

\section{Ethics approval and consent to participate}

Not applicable

\section{Consent for publication}

Not applicable

\section{Availability of data and materials}

Pass port data of 150 Vernonia galamensis samples representing the 10 populations used in the current study are provided in Additional file 1. Unweighted neighbor joining based clustering of 150 Vernonia galamensis accessions for 20 polymorphic SSR 
markers are provided in Additional file 2. AMOVA variation pie chart for 150 Vernonia galamensis accessions from ten populations in Ethiopia are provided in Additional file 3.

\section{Competing interests}

The authors declare that they have no competing interests.

\section{Funding}

This work is financially supported by Addis Ababa University's Research Project and Huazhong Agricultural University, China through the link of Swedish International Development Cooperation Agency (SIDA).The role of the funding is limited to the field work and laboratory facilities.

\section{Authors' contributions}

$\mathrm{AM}, \mathrm{KT}$ and $\mathrm{KD}$ designed the study. AM and $\mathrm{XH}$ coordinate and carried out the laboratory work. AM performed statistical data and wrote the manuscript. All the authors read and approved the final manuscript.

\section{Acknowledgements}

This is the part of author's PhD thesis work. The authors would like to thank Addis Ababa University and Adama Science and Technology University for material and technical supports for this research. We would also like to thank Melka Werer and Wondo Genet Agricultural Research Center for they created good working condition during field work, and the Ethiopian Biodiversity Institute (EBI) for providing accessions and for allowing the transfer of the study material to China, and the Huazhong Agricultural University for providing laboratory facilities to conduct this research

\section{References}

1. Thompson AE, Dierig DA, Johnson ER, Dahlquist GH, Kleiman R. Germplasm development of Vernonia galamensis as a new industrial oilseed crop. Ind. Crops Prod. 1994a; https://doi.org/10.1016/0926-6690 (94)90066-3.

2. Baye T, Kebede H, Belete K. Agronomic evaluation of Vernonia galamensis germplasm collected from eastern Ethiopia. Industrial Crops and Products. 2001; doi: 10.1016/S0926-6690(01)00082-6.

3. Mideksa A, Tesfaye K, Dagne K. Centrapalus pauciflorus (Willd.) H. Rob. Neglected potential oil crop of Ethiopia, agromorphological characterization. Resour. Crop. Evol. 2018; https://doi.org/10.1007/s10722-018-0719-1.

4. Mebrahtu T, Gebremariam T, Kidane A, Araria W. Performance of Vernonia galamensis as a potential and viable industrial oil plant in Eritrea: yield and oil content. African Journal of Biotechnology. 2009;8(4): 635-640.

5. Shimelis H, Mashela PW, Hugo A. Performance of Vernonia as an alternative industrial oil crop in Limpopo Province of South Africa. Crop Science. 2008; 48(1): 236. doi: 10.2135/cropsci2007.06.0331.

6. Gilbert MG. East African Vernonieae (Compositae), a revision of the Vernonia galamensis Kew Bulletin. 1986; 41 (1): 19-35.

7. Perdue RE, Carlson KD, Gilbert MG. Vernonia galamensis, Potential new crop source of epoxy acid. Economic Botany. 1986; doi: 10.1007/BF02858947.

8. Thompson AE, Dierig DA, Kleiman R. Characterization of Vernonia galamensis germplasm for seed oil content, fatty acid composition, seed weight, and chromosome number. Industrial Crops and Products. 1994b; doi: 10.1016/0926-6690(94)90121$\mathrm{X}$.

9. Thompson AE, Dierig DA, Kleiman R. Variation in Vernonia galamensis flowering characteristics, seed oil and vernolic acid contents. Industrial Crops and Products. 1994c; doi: 10.1016/0926-6690(94)90065-5.

10. Bhardwaj HL, Hamama AA, Dierig DA. Fatty acids in vernonia produced in the Mid-Atlantic region of the united states. Journal of the American Oil Chemists Society. 2007; 84(4): 393-397. doi: 10.1007/s11746-007-1043-7.

11. Baye T, Becker HC. Analyzing seed weight, fatty acid composition, oil, and protein contents in Vernonia galamensis germplasm by near-infrared reflectance spectroscopy. JAOCS, Journal of the American Oil Chemists' Society. (2004; doi: 10.1007/s11746004-955-y. 
12. Baye T, Becker HC. Exploration of Vernonia galamensis in Ethiopia, and Variation in Fatty Acid Composition of Seed Oil.Genetic Resources and Crop Evolution. 2005; 52(7): 805-811. doi: 10.1007/s10722-003-6086-5.

13. Ramalema SP, Shimelis H, Ncube I, Kunert KK, Mashela PW. Genetic analysis among selected vernonia lines through seed oil content, fatty acids and RAPD DNA African Journal of Biotechnology. 2010; 9 (2):117-122.

14. Baye T, Becker HC, Witzke-Ehbrecht, SV. Vernonia galamensis, a natural source of epoxy oil: variation in fatty acid composition of seed and leaf lipids. Industrial Crops and Products. 2005; 21(2): 257-261. doi: 10.1016/j.indcrop.2004.04.003.

15. Idrees M, Irshad M. Molecular markers in plants for analysis of genetic diversity: European Academic Research. $2014 ; 1$ (1).

16. Govindaraj M, Vetriventhan M, Srinivasan M. Importance of genetic diversity assessment in crop plants and its recent advances. Genet Res Int. 2015; doi: 10.1155/2015/431487.

17. Bhandari HR, Bhanu AN, Srivastava K, Singh MN, Shreya AH. Assessment of genetic diversity in crop plants - An overview. Adv. Plants. Agric. Res. 2017; 7(3): 00255. DOI: 15406/apar.2017.07.00255.

18. Varshney RK, Graner A, Orrells ME. Genic microsatellite markers in plants: features and applications. TRENDS in Biotechnology. 2005; 23 (1): 48-55.

19. Anumalla M, Roychowdhury R, Geda CK, Mazid M, Rathoure AK. Utilization of plant genetic resources and diversity analysis tools for sustainable crop improvement with special emphasis on rice. International Journal of Advanced Research. 2015; 3 (3): 11551175.

20. Gilbert JE, Lewis RV, Wilkinson MJ, Caligari PDS. Developing an appropriate strategy to assess genetic variability in plant germplasm collections. Theor. Appl. Genet. 1999; 98:1125-1131.

21. Doyle JJ, Doyle JL. Isolation of plant DNA from fresh tissue. Focus. 1990; 12:13-15.

22. Narina SS, Andebrhana T, Mohamed Al, Bhardwaj HL. Functional classification of ESTs from vernonia (Vernonia galamensis) cDNA library. Industrial Crops and Products. 2012; 36: 370-375.

23. Peakall R, Smouse PE. GenAlEx 6.503: genetic analysis in excel. Population genetic software for teaching and research-an update. Bioinformatics. 2012; 28: 2537-2539.

24. Perrier X, Jacquemoud-Collet JP. DARwin software. 2006; http://darwin.cirad.fr/ darwin.

25. Andrew R. FigTree: Tree figure drawing tool, Version 1.4.4. Institute of Evolutionary Biology, University of Edinburgh. 2018.

26. Pritchard JK, Stephens M, Donnelly P. Inference of population structure using multi locus genotype data. Genetics. 2000; 155:945-959.

27. Evanno G, Regnaut S, Goudet J. Detecting the number of clusters of individuals using the software STRUCTURE: a simulation study. Ecol. 2005; 14: 2611-2620.

28. Earl DA, Von Holdt BM. STRUCTURE HARVESTER: A website and program for visualizing STRUCTURE output and implementing the Evanno method. Genet. Reso. 2012; 4: 359-361.

29. Kopelman NM, Mayzel J, Jakobsson M, Rosenberg NA, Mayrose I. CLUMPAK: A program for identifying clustering modes and packaging population structure inferences across k. Ecol. Res. 2015; 15(5): 1179-1191.

30. Nei M. Analysis of gene diversity in subdivided populations. Nat. Acad. Sci. USA. 1972; 70: 3321-3323.

31. Gilbert KJ, Andrew RL, Bock DG, Franklin MT, Kane N C. et al. Recommendations for utilizing and reporting population genetic analyses: the reproducibility of genetic clustering using the program STRUCTURE. Ecol. 2012; 1-6.

32. Aikpokpodion PO, Abebe J, IGWE D. Genetic diversity in Vernonia amygdalina Delile accessions revealed by random amplified polymorphic DNAs (RAPDs). Journal of Biotechnology. 2018; 99(2): 147-152.

33. Nwakanma NM, Oboh BO, Adekoya KO, Ogunkanmi LA. Genetic Diversity of Vernonia as Revealed By Random Amplified Polymorphic DNA (RAPD) Markers. Acad. J. Biolog. Sci. 2018; 9(1): 27-38. ISSN 2090-3812

34. IPGRI and Cornell University. Genetic Diversity Analysis with Molecular Data: Learning module. 2003; 1-71.

\section{Tables}

Table 1. Vernonia galamensis samples used in the current study 


\begin{tabular}{lcccc}
\hline Population & Sample size & Altitude ranges $(\mathrm{m})$ & \multicolumn{2}{c}{ Co-ordinates } \\
\cline { 3 - 5 } & & & Latitude ranges & Longitude ranges \\
\hline Borena & 15 & $1090-1200$ & $4^{\circ} 88^{\prime}-4^{\circ} 90^{\prime} \mathrm{N}$ & $39^{\circ} 35^{\prime}-39^{\circ} 40^{\prime} \mathrm{E}$ \\
\hline East Showa & 15 & $1630-1643$ & $7^{\circ} 56^{\prime}-8^{\circ} 90^{\prime} \mathrm{N}$ & $38^{\circ} 43^{\prime}-39^{\circ} 70^{\prime} \mathrm{E}$ \\
\hline West Arsi & 15 & $2000-2143$ & $7^{\circ} 15^{\prime}-8^{\circ} 90^{\prime} \mathrm{N}$ & $38^{\circ} 38^{\prime}-38^{\circ} 42^{\prime} \mathrm{E}$ \\
\hline East Harerghe & 16 & $1574-2750$ & $9^{\circ} 06^{\prime}-9^{\circ} 25^{\prime} \mathrm{N}$ & $41^{\circ} 25^{\prime}-41^{\circ} 38^{\prime} \mathrm{E}$ \\
\hline West Harerghe & 14 & $1393-1889$ & $8^{\circ} 56^{\prime}-9^{\circ} 13^{\prime} \mathrm{N}$ & $40^{\circ} 52^{\prime}-42^{\circ} 27^{\prime} \mathrm{E}$ \\
\hline West Gojjam & 14 & $1205-2560$ & $10^{\circ} 27^{\prime}-10^{\circ} 30^{\prime} \mathrm{N}$ & $38^{\circ} 12^{\prime}-39^{\circ} 09^{\prime} \mathrm{E}$ \\
\hline South Wollo & 16 & $1866-2630$ & $9^{\circ} 51^{\prime}-11^{\circ} 08^{\prime} \mathrm{N}$ & $39^{\circ} 10^{\prime}-39^{\circ} 38^{\prime} \mathrm{E}$ \\
\hline Sidama & 15 & $1708-1780$ & $6^{\circ} 51^{\prime}-7^{\circ} 15^{\prime} \mathrm{N}$ & $37^{\circ} 45^{\prime}-38^{\circ} 27^{\prime} \mathrm{E}$ \\
\hline Konso & 15 & $1500-1650$ & $5^{\circ} 15^{\prime}-5^{\circ} 20^{\prime} \mathrm{N}$ & $37^{\circ} 27^{\prime}-37^{\circ} 40^{\prime} \mathrm{E}$ \\
\hline Derashie & 15 & $1395-1450$ & $6^{\circ} 18^{\prime}-6^{\circ} 25^{\prime} \mathrm{N}$ & $36^{\circ} 53^{\prime}-37^{\circ} 09^{\prime} \mathrm{E}$ \\
\hline
\end{tabular}

Table 2. Primer sequences, annealing temperature and amplicon sizes which were used for genetic diversity studies in Vernonia galamensis

\begin{tabular}{|c|c|c|c|c|c|}
\hline $\begin{array}{c}\text { SSR } \\
\text { primers }\end{array}$ & $\begin{array}{c}\text { SSR motifs } \\
\left(5^{\prime}-3^{\prime}\right)\end{array}$ & Forward Sequence $\left(5^{\prime}-3^{\prime}\right)$ & Reverse Sequence $\left(5^{\prime}-3^{\prime}\right)$ & $\begin{array}{c}\text { Annealing } \\
\text { tem }\end{array}$ & $\begin{array}{l}\text { Product } \\
\text { Size }\end{array}$ \\
\hline Vg-001 & (AT) 12 & CTTGATTTTGTGGGGACCTAAGTG & TAGGAATGGAATAGAATGGATCGG & 56 & 135 \\
\hline Vg-002 & (TC) 12 & GGGTTGTGGGGAGAGATAGAGATA & AGCCAAGTTACGCATAGACATCTG & 56 & 146 \\
\hline Vg-003 & (TC) 24 & GTGAGCGGGGATCTTCACTTC & GAGAAAGCGAGCATCAACAGACTT & 56 & 142 \\
\hline Vg-004 & (CCA)12 & ACCATACAGTCCCGCATGAATATC & GCTCCTGGAAATGGAGGATAGAAT & 58 & 145 \\
\hline Vg-005 & $(\mathrm{AAG}) 12$ & AGCTTAAACAAGAACAAACCGCTG & TGCGAAGGCTTACCAGTTACAAAC & 56 & 157 \\
\hline $\mathrm{Vg}-006$ & $(\mathrm{ACA}) 12$ & ATCAGCGTTGCTTGAAAAGAGTG & AAACTCATCGCTCAAACTCAAACG & 58 & 101 \\
\hline Vg-007 & (TCT)18 & ATGACGATGCAACTCACCGTT & CGGAGAGGTTTGGTAGGGTAAGAT & 56 & 136 \\
\hline Vg-008 & (GAT)24 & ATGTCTTCCAAATCGAGGATGGTA & AATTTTTGCAGCTAAGCCAGTGAG & 58 & 101 \\
\hline Vg-009 & (GGA)15 & ATTGAAGGATGAACGGACAGAGTC & GTATCACATCACGTCGTCCACATC & 58 & 127 \\
\hline Vg-010 & (ATG)15 & CAAAGGGAAGATGCACCTAGAGAA & ATCAAACCTGCTGCTTTTCAAGTC & 58 & 130 \\
\hline Vg-011 & (TGA)12 & GCACAATCAGACTTGAGACCAAGA & GCAGTGATCAGCCATAGTGCATAC & 58 & 130 \\
\hline Vg-012 & (CGC)12 & GGGCTGAGCAAATACAGCAGAC & AGGATCTTCTTGTTGGTGTGGAAA & 58 & 150 \\
\hline Vg-013 & (CAG)15 & GGGGCGTTTCCTTGATTTTG & СTCTTCACCTGCCATCTTTTCTGT & 56 & 93 \\
\hline Vg-014 & $(\mathrm{CAA}) 12$ & GTAGCAGCAGCAGTTCACTACCAC & CAAAATCCTCACAAACTTCACACG & 56 & 132 \\
\hline Vg-015 & (GGC)18 & GTGCTACAACGGTGGTACATCAAG & TCATTGATTCCATGCTGAAATAGC & 56 & 159 \\
\hline Vg-016 & (GGT)12 & GTTAGAGATGGGTTTGAAGAGCGA & ССТТАССААСТССААСАССАСТТG & 58 & 139 \\
\hline Vg-019 & (CTTCAC)24 & GGGTCTCCATCTATTCACCTTCAA & AAGGAGCGTGAGCTAGAAGAAGC & 56 & 158 \\
\hline Vg-021 & (GTC)15 & TGAAGAAGAAGGTTTCCCAAATCA & GATGCATTGACATCACGTAGAAGC & 56 & 155 \\
\hline Vg-024 & (ATC)15 & TTGGATGTCGAAAAAGATGAGGTT & TTCTCССТСТGTTTCAACACСТTC & 56 & 144 \\
\hline Vg-030 & (CT) 12 & TCAAACACACTCСССAATTTCTCT & GCTGCCGATTGATCAAATTACACT & 56 & 100 \\
\hline
\end{tabular}

Table 3: Summary of genetic parameters revealed by using 20 SSR markers for Vernonia galamensis populations collected from different regions of Ethiopia 


\begin{tabular}{lccccccccc}
\hline Locus & MAF & Na & Ne & I & Ho & He & uHe & F & PIC \\
\hline Vg-01 & 0.85 & 3 & 2.80 & 1.06 & 0.25 & 0.48 & 0.49 & 0.25 & 0.80 \\
Vg-02 & 0.77 & 5 & 3.26 & 1.36 & 0.13 & 0.50 & 0.51 & 0.73 & 0.96 \\
\hline Vg-03 & 0.45 & 6 & 4.79 & 1.67 & 0.36 & 0.65 & 0.64 & 0.77 & 0.62 \\
\hline Vg-04 & 0.52 & 3 & 2.28 & 0.90 & 0.07 & 0.59 & 0.61 & 0.88 & 0.64 \\
Vg-05 & 0.64 & 3 & 2.01 & 0.89 & 0.13 & 0.60 & 0.63 & 0.78 & 0.50 \\
\hline Vg-06 & 0.54 & 5 & 3.69 & 1.44 & 0.13 & 0.44 & 0.45 & 0.70 & 0.86 \\
\hline Vg-07 & 0.61 & 4 & 3.46 & 1.31 & 0.20 & 0.58 & 0.60 & 0.66 & 0.57 \\
\hline Vg-08 & 0.59 & 5 & 3.26 & 1.36 & 0.20 & 0.61 & 0.63 & 0.67 & 0.89 \\
\hline Vg-09 & 0.61 & 3 & 2.60 & 1.01 & 0.23 & 0.45 & 0.47 & 0.49 & 0.87 \\
Vg-10 & 0.60 & 4 & 3.81 & 1.36 & 0.07 & 0.46 & 0.48 & 0.86 & 0.86 \\
Vg-11 & 0.56 & 4 & 2.03 & 0.95 & 0.13 & 0.23 & 0.24 & 0.42 & 0.93 \\
\hline Vg-12 & 0.57 & 3 & 2.53 & 1.01 & 0.07 & 0.46 & 0.48 & 0.86 & 0.84 \\
\hline Vg-13 & 0.49 & 4 & 3.57 & 1.33 & 0.13 & 0.48 & 0.50 & 0.72 & 0.73 \\
Vg-14 & 0.60 & 3 & 2.27 & 0.95 & 0.27 & 0.48 & 0.50 & 0.44 & 0.77 \\
\hline Vg-15 & 0.76 & 4 & 2.68 & 1.16 & 0.08 & 0.50 & 0.52 & 0.85 & 0.88 \\
\hline Vg-16 & 0.64 & 2 & 1.99 & 0.86 & 0.07 & 0.36 & 0.37 & 0.81 & 0.78 \\
\hline Vg-19 & 0.58 & 4 & 3.46 & 1.31 & 0.33 & 0.64 & 0.67 & 0.48 & 0.70 \\
\hline Vg-21 & 0.51 & 5 & 4.41 & 1.55 & 0.05 & 0.60 & 0.62 & 0.89 & 0.86 \\
\hline Vg-24 & 0.67 & 5 & 3.81 & 1.46 & 0.27 & 0.62 & 0.65 & 0.57 & 0.53 \\
\hline Vg-30 & 0.61 & 3 & 2.53 & 1.01 & 0.07 & 0.28 & 0.29 & 0.76 & 0.55 \\
\hline Mean & 0.61 & 3.9 & 3.06 & 1.20 & 0.16 & 0.50 & 0.52 & 0.68 & 0.76 \\
\hline
\end{tabular}

Key: MAF $=$ major allele frequency, $\mathrm{Na}=$ number of different alleles, $\mathrm{Ne}=$ number of effective alleles, $\mathrm{I}=\mathrm{Shannon}$ 's information index, $\mathrm{Ho}=$ observed heterozygosity, $\mathrm{He}=$ expected heterozygosity, $\mathrm{uHe}=$ unbiased expected heterozygosity, $\mathrm{F}$ = fixation index, $\mathrm{PIC}=$ polymorphic information content.

Table 4. Important allelic values recorded in the ten populations of Vernonia galamensis

\begin{tabular}{lcccccccc}
\hline Population & $\mathrm{N}$ & $\mathrm{Na}$ & $\mathrm{Ne}$ & $\mathrm{I}$ & $\mathrm{Ho}$ & $\mathrm{He}$ & Uhe & $\mathrm{F}$ \\
\hline Borena & 15 & 3.00 & 1.98 & 0.76 & 0.13 & 0.48 & 0.50 & 0.74 \\
\hline Sidama & 15 & 4.00 & 2.03 & 0.74 & 0.12 & 0.47 & 0.51 & 0.72 \\
\hline East Showa & 15 & 5.00 & 4.74 & 0.82 & 0.15 & 0.51 & 0.55 & 0.68 \\
West Arsi & 15 & 3.00 & 2.07 & 0.70 & 0.13 & 0.45 & 0.47 & 0.70 \\
\hline E. Harerghe & 16 & 4.00 & 3.68 & 0.79 & 0.12 & 0.49 & 0.53 & 0.73 \\
West Harerghe & 14 & 4.00 & 3.12 & 0.77 & 0.16 & 0.48 & 0.50 & 0.73 \\
Gojjam & 14 & 3.00 & 2.33 & 0.70 & 0.13 & 0.47 & 0.49 & 0.64 \\
\hline Wollo & 16 & 4.00 & 2.74 & 0.72 & 0.14 & 0.48 & 0.52 & 0.68 \\
\hline Konso & 15 & 3.00 & 2.21 & 0.71 & 0.13 & 0.45 & 0.48 & 0.72 \\
\hline Derashie & 15 & 2.00 & 1.74 & 0.75 & 0.09 & 0.43 & 0.47 & 0.81 \\
\hline Average across population & 15 & 3.50 & 2.70 & 0.75 & 0.13 & 0.47 & 0.50 & 0.72 \\
\hline
\end{tabular}

Key: $\mathrm{Na}=$ number of different alleles, $\mathrm{Ne}=$ number of effective alleles, $\mathrm{I}=$ Shannon's diversity index, Ho $=$ observed heterozygosity, $\mathrm{He}=$ expected heterozygosity, $\mathrm{uHe}=$ unbiased expected heterozygosity, $\mathrm{F}=$ fixation index, PIC = polymorphic information content

Table 5. Analysis of molecular variance (AMOVA) showing the distribution of genetic diversity within and among populations and among individuals of Vernonia galamensis collected from different regions of Ethiopia 


\begin{tabular}{|c|c|c|c|c|c|c|c|c|}
\hline Source & Df & SS & MS & Est. Var. & \% Variation & F-Statistics & Value & $\bar{P}$ \\
\hline Among Populations & 9 & 322.71 & 35.86 & 0.76 & $11 \%$ & $\overline{\mathrm{F}_{\mathrm{st}}}$ & 0.101 & 0.001 \\
\hline Among Individual & 140 & 1842.01 & 13.16 & 6.39 & $67 \%$ & $\mathrm{~F}_{\text {is }}$ & 0.946 & 0.001 \\
\hline Within individual & 150 & 55.21 & 0.37 & 0.37 & $22 \%$ & $\mathrm{~F}_{\mathrm{it}}$ & 0.951 & 0.001 \\
\hline Total & 299 & 2219.93 & & 7.52 & $100 \%$ & & & \\
\hline
\end{tabular}

Df $=$ Degrees of Freedom; SS = Sum of Squares; MS = Mean Square; Est. Var. = Estimated Variability

Table 6. Pairwise population matrix of Nei standard genetic distance (GD)

\begin{tabular}{lcccccccccc}
\hline Population & BOR & SID & ESH & WAS & EHG & WHG & GOJ & WOL & KON & DER \\
& & & & & & & & & & \\
\hline BOR & $* *$ & 0.47 & 0.37 & 0.43 & 0.57 & 0.40 & 0.46 & 0.36 & 0.24 & 0.41 \\
\hline SID & & $* *$ & 0.59 & 0.37 & 0.39 & 0.54 & 0.51 & 0.44 & 0.50 & 0.36 \\
\hline ESH & & & $* *$ & 0.49 & 0.44 & 0.47 & 0.34 & 0.29 & 0.42 & 0.27 \\
\hline WAS & & & & $* *$ & 0.44 & 0.38 & 0.45 & 0.36 & 0.35 & 0.47 \\
\hline EHG & & & & & $* *$ & 0.47 & 0.47 & 0.40 & 0.39 & 0.25 \\
WHG & & & & & & $* *$ & 0.41 & 0.35 & 0.31 & 0.41 \\
\hline GOJ & & & & & & & $* *$ & 0.36 & 0.37 & 0.38 \\
\hline WOL & & & & & & & & $* *$ & 0.37 & 0.42 \\
\hline KON & & & & & & & & & $* *$ & 0.35 \\
\hline DER & & & & & & & & & & $* *$ \\
\hline
\end{tabular}

Keys $:$ BOR $=$ Borena, SID $=$ Sidama, ESH $=$ East Showa, WAS $=$ West Arsi, EHG $=$ East Harerghe, WHG $=$ West Harerghe, GOJ $=$ Gojjam, WOL $=$ Wollo, $\mathrm{KON}=$ Konso, DER $=$ Derashie

\section{Figures}




\section{Legend}

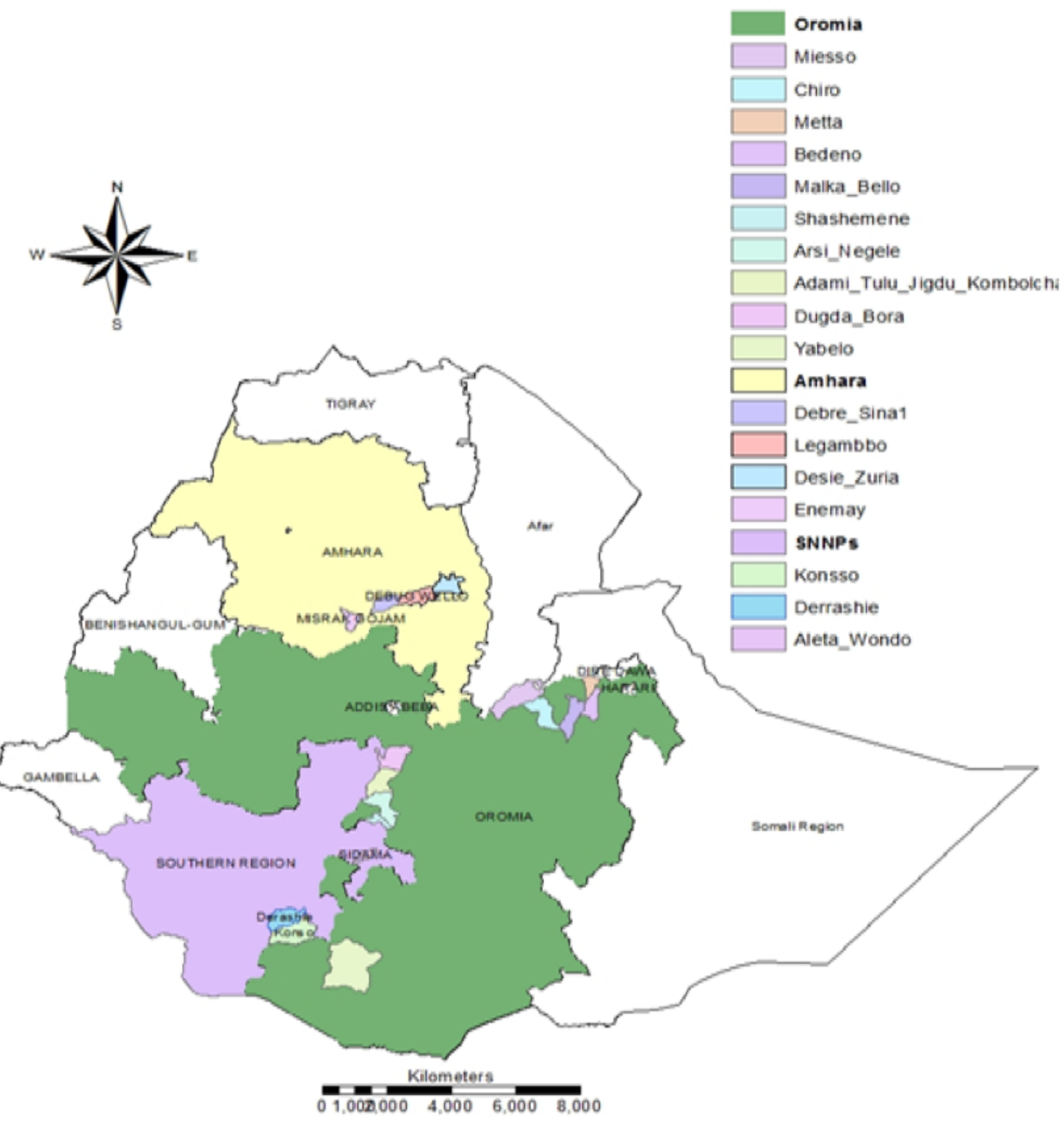

\section{Figure 1}

Map of Ethiopia showing Vernonia galamensis collection sites within three of the Federal Regions. The map was original and constructed using geographic coordinates and elevation data gathered from each collection sites using global positioning system (GPS) that represent the 10 populations. 


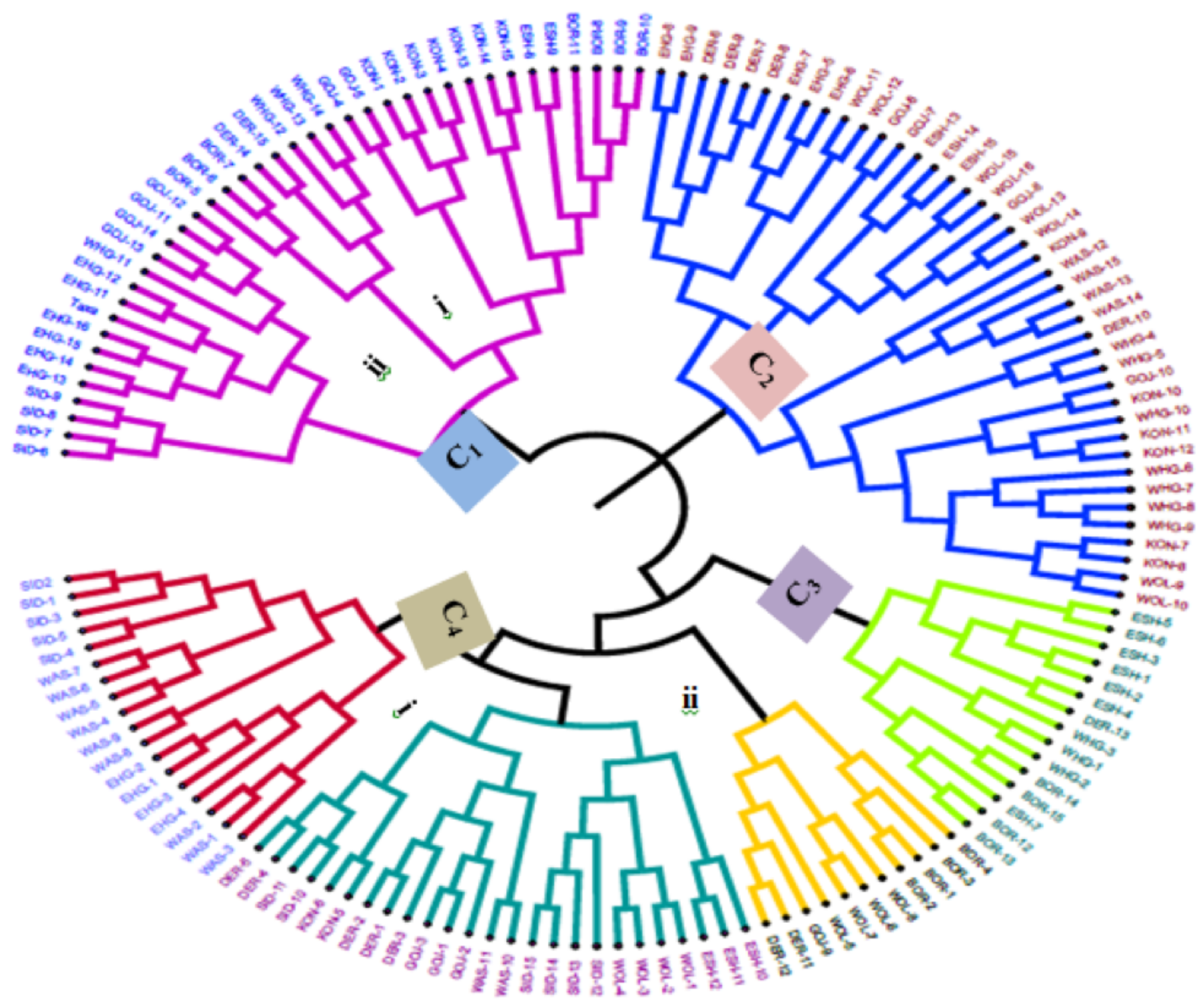

1.1

Figure 2

Neighbor-joining tree of the 150 Vernonia galamensis accessions constructed by Darwin software program. Keys: BOR = Borena, SID $=$ Sidama, ESH $=$ East Showa, WAS = West Arsi, EHG $=$ East Harerghe, WHG = West Harerghe, GOJ = Gojjam, WOL $=$ Wollo, $\mathrm{KON}=$ Konso, DER = Derashie 


\section{Principal Coordinates (PCoA)}

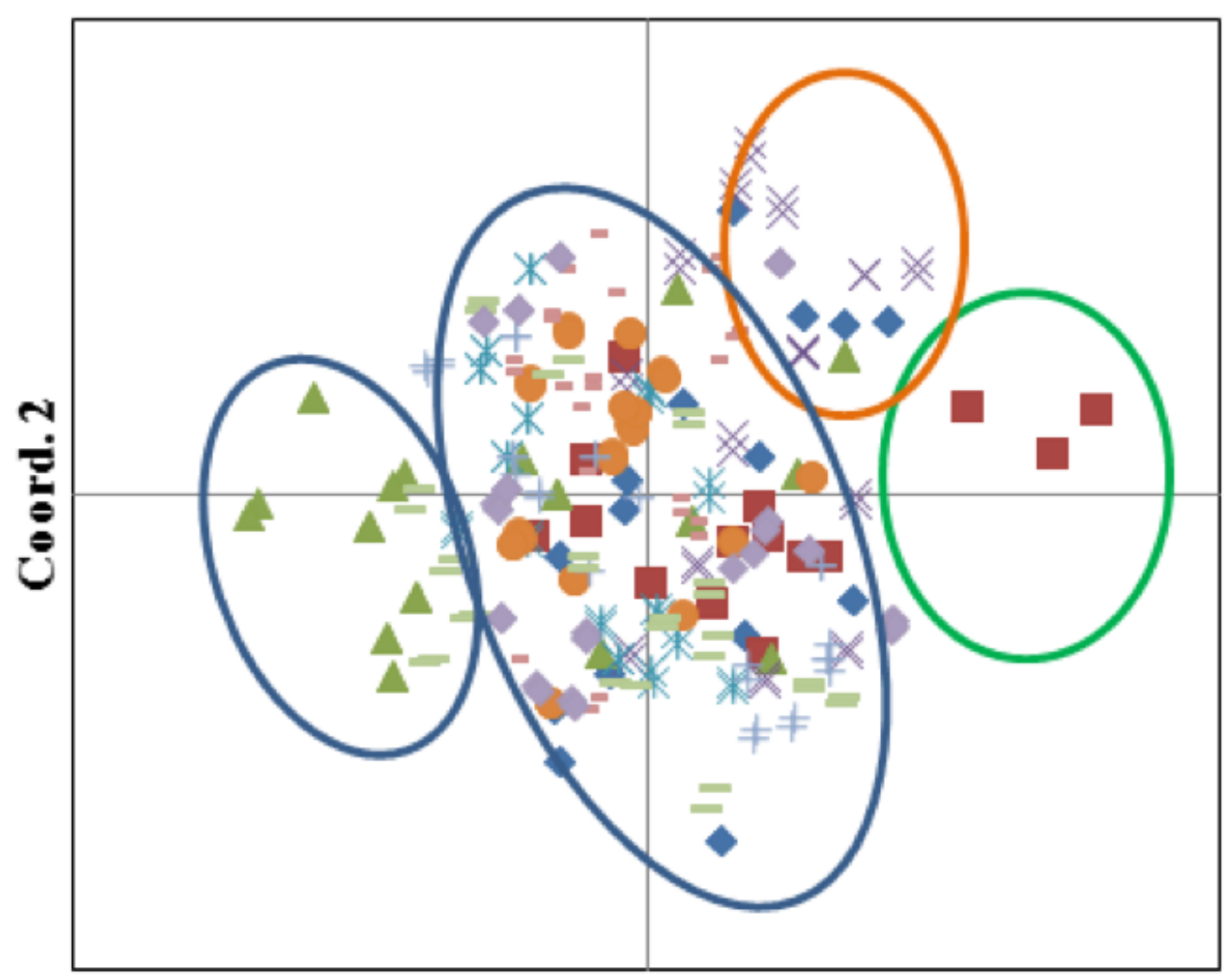

Borena

Sidama

$\Delta$ E.Showa

$\times$ West Arsi

* East Harerghe

- West Harerghe

+ Gojjam

-Wollo

- Konso

$\rightarrow$ Derashie

\section{Coord. 1}

Figure 3

Two dimensional scaling principal coordinate analyses of 150 Vernonia galamensis accessions of ten populations. 

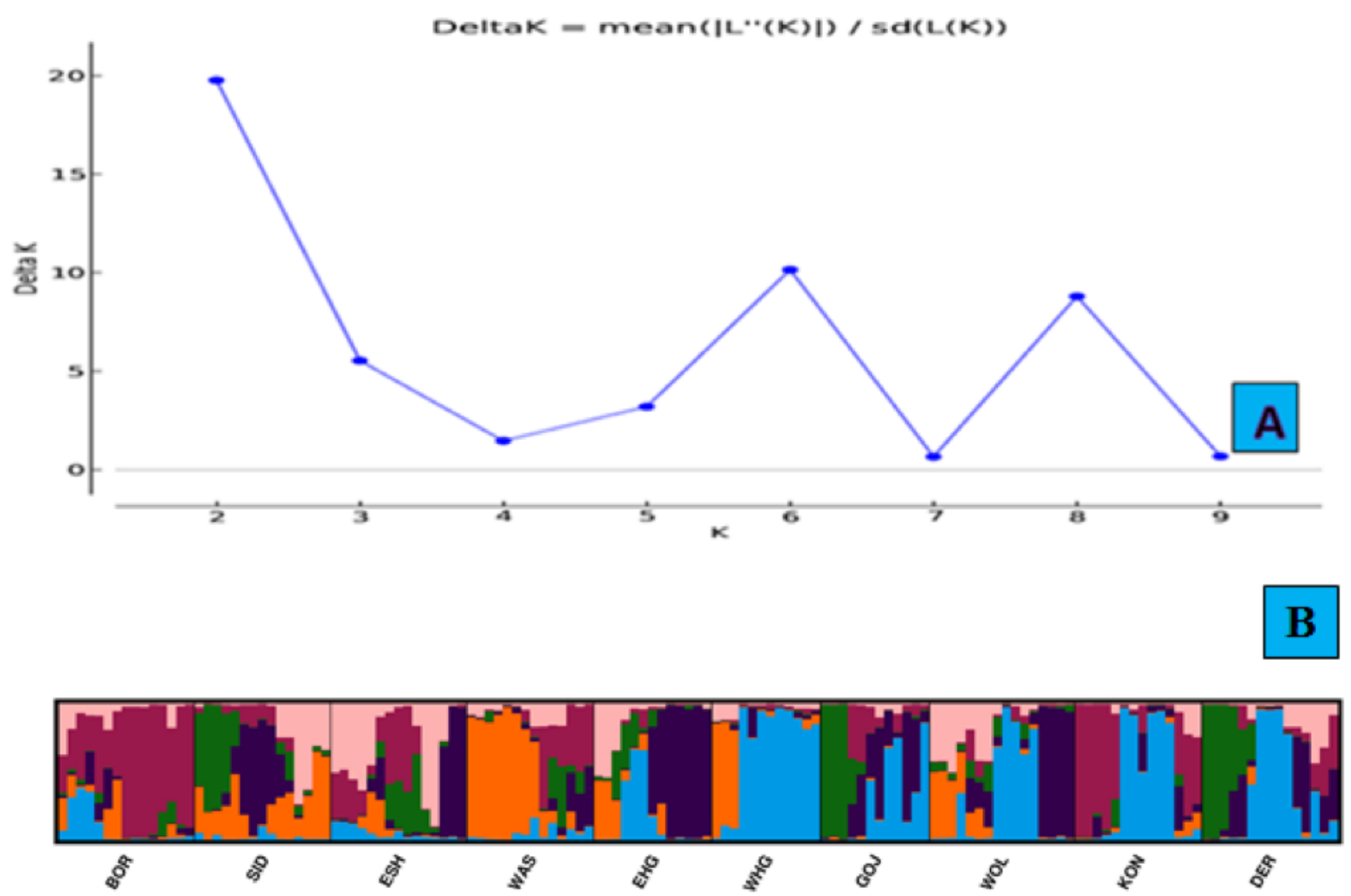

Figure 4

Delta $\mathrm{K}$ values estimated according to Evanno et al. 2005 Method $(A)$ and Bayesian model-based estimation of population structure $(K=6)(B)$ for 150 Vernonia galamensis accessions from different growing regions of Ethiopia. Keys: BOR = Borena, SID = Sidama, $\mathrm{ESH}=$ East Showa, WAS $=$ West Arsi, EHG $=$ East Harerghe, $\mathrm{WHG}=$ West Harerghe, GOJ $=$ Gojjam, WOL $=$ Wollo, $\mathrm{KON}=\mathrm{Konso}, \mathrm{DER}=$ Derashie

\section{Supplementary Files}

This is a list of supplementary files associated with this preprint. Click to download.

- Supplementaryfile.docx 